\title{
PLANEJAMENTO DE CENÁRIOS PARA ANÁLISES DE APLICAÇÃO DA LAMA VERMELHA*
}

\author{
Léo Daiki Shinomiya ${ }^{1}$ \\ Joner Oliveira Alves ${ }^{2}$ \\ Jefferson de Oliveira Gomes ${ }^{3}$
}

\begin{abstract}
Resumo
O planejamento de cenários é uma ferramenta empregada como um mecanismo competitivo que entrega uma visão para um futuro passível de acontecer, baseado em fatos atuais e históricos. Adaptado para ser aplicado a resíduos industriais, este método de planejamento de cenários pode ser descrito em oito etapas. Neste trabalho é apresentada a $1^{\text {a }}$ etapa, que mostra o uso de pesos e critérios para definir as aplicações mais adequadas para a Lama Vermelha a partir de uma infraestrutura disponível localmente. A Lama Vermelha é gerada em larga escala pela indústria do Alumínio, somente no estado do Pará são gerados 5,4 milhões de toneladas anualmente, que impacta diretamente nos custos desta indústria em função de seu tratamento e estocagem. Os resultados guiam definições para as aplicações mais adequadas para a Lama vermelha, sendo destacado o emprego na fabricação de cerâmica vermelha e na produção do cimento.
\end{abstract}

Palavras-chave: Planejamento de cenários; Estratégia; Lama vermelha; Resíduo.

\section{SCENARIO PLANNING TO RED MUD APPLICATION ANALYSES}

\begin{abstract}
The scenario planning is a tool used as a competitive mechanism that delivers a vision for a future likely to happen based on current and historical facts. Adapted to be applied to industrial waste, this scenario planning method can be described in eight steps. This paper presents the first stage, which shows the use of weights and criteria to define the most suitable applications for the red mud from a locally available infrastructure. The red mud is generated on a large scale by the aluminum industry; only in the state of Pará are generated 5.4 million tons annually, which directly affects the costs of this industry due to its treatment and storage. The results guide definitions for the most appropriate applications for the red mud and highlighted the use in the manufacture of red ceramics and cement production.
\end{abstract}

Keywords: Scenarios planning; Strategy; Red mud; Waste.

1 M.Sc., Assistente de Pesquisa, Instituto SENAI de Inovação em Tecnologias Minerais. Federação das Indústrias do Estado do Pará - FIEPA, Belém - PA, Brasil.

2 Dr., Diretor do Instituto SENAI de Inovação em Tecnologias Minerais. Federação das Indústrias do Estado do Pará - FIEPA, Belém - PA, Brasil.

3 Dr., Professor do Departamento de Engenharia Mecânica, Instituto Tecnológico de Aeronáutica ITA, São José dos Campos - SP, Brasil. 


\section{INTRODUÇÃO}

O planejamento de cenários é uma ferramenta da administração desenvolvida para criar situações baseadas em dados históricos e atuais objetivando a tomada de decisão estratégica. O termo "planejamento", segundo [1] "é o trabalho de preparação para a tomada de decisão, seguindo roteiros e métodos determinados". Com um mercado dinâmico, as indústrias tendem a se ajustar, buscando tendências de seu mercado, atuando de formas mais estratégicas e, portanto, tornando-se mais competitiva. Nesta dinâmica, a maximização da eficiência e da flexibilização no processo produtivo são fatores que garantem um posicionamento mais competitivo. No entanto, isso apenas não garante um conforto de mercado, é preciso ter ações ágeis na tomada de decisão, ou seja, ter em vista possíveis ocorrências do mercado e estar preparado para tomar decisões. Este delay na tomada de decisão traduz o ritmo de produção e consequentemente na entrega do produto para o cliente.

$O$ resíduo gerado além de ser responsabilidade do gerador, deve ser tratada e disposta de maneira adequada. A Política Nacional de Resíduos Sólidos, descrita pela Lei [3], estabelece princípios, objetivos, diretrizes, metas e ações. Em seu artigo 13, item I, subitem $f$, define resíduos industriais como: os gerados nos processos produtivos e instalações industriais.

A cadeia de alumínio no Pará movimentou $R \$ 7,25$ bilhões e transformou cerca de 6 milhões de toneladas de Alumina em 2014. A cada tonelada de alumina produzida são gerados cerca de 0,7 a 0,9 toneladas de resíduos chamado lama vermelha. Este rejeito possui característica alcalina devido a adição de compostos químicos usados no processo de separação do metal da ganga, além de demandar grandes áreas para a sua estocagem. Estudos mostram que sua composição possui vários elementos de interesse econômico para outros setores industriais [4,5]. Além disso, o grande impacto ambiental que este rejeito pode gerar é de suma importância considerar tal perspectiva uma alternativa para reduzir o montante deste material depositado em barragens de rejeitos. Isto se faz atualmente um grande desafio para a indústria do alumínio. $\mathrm{Na}$ área da construção civil a lama apresenta potencial para a aplicação em cimento do tipo Portland e como matéria prima de materiais cerâmicos na construção de tijolos estruturais e telhas por possuir em sua composição elementos que agregam requisito da matéria prima deste setor. Na indústria química como catalisadores, como reagentes fotodegradadores, como capturador de $\mathrm{CO}_{2}$, como adsorventes de metais pesados e de compostos orgânicos, como remediadores de solos ácidos devido a alcalinidade da lama. Na metalurgia, extraindo óxidos puros como o óxido de ferro $\left(\mathrm{Fe}_{2} \mathrm{O}_{3}\right)$ para a produção de aços, o óxido de titânio $\left(\mathrm{TiO}_{2}\right)$ para a produção de tintas, corantes para alimentos, cosméticos, catalisadores, protetores solar e além do potencial de serem transformado em ligas especiais de titânio para a aplicação em próteses e na área aeroespacial. Na indústria nuclear como imobilizador de rejeitos nucleares ainda em fase de testes. Para selecionar estas possíveis aplicações fez-se necessário o ranking das aplicações considerando critérios voltados à estrutura de beneficiamento presente no estado.

O objetivo deste trabalho é desenvolver o a primeira etapa do método de planejamento de cenários para aplicação de resíduos industriais, especificamente da lama vermelha em produtos comerciais que demandam grande quantidade de matéria-prima, como uma forma de amenizar o volume deste rejeito estocado e que é gerado em larga escala anualmente. O desenvolvimento de cenários desafia hipóteses, levanta questões relevantes, prospecta grande quantidade de dado e instiga os gestores na tomada de decisão. 


\section{MATERIAIS E MÉTODOS}

O presente trabalho reuniu informações sobre o resíduo e da indústria beneficiadora que através de métodos de construção de cenários, aplicá-los como aditivos ou substitutos parciais em produtos industriais. A metodologia de planejamento de cenários foi baseada na escola Norte Americana pelo seu caráter intuitivo, com maior objetividade e por possuir maior difusividade de métodos que o método Francês $[6,8,9,10]$. Além dos autores citados, Goodwin e Wright, descrevem etapas que sintetizam esta lógica [11]. Este trabalho adaptou estas etapas descrita em 8 passos, sendo o último passo a geração dos primeiros indicadores não citado por Schwartz [6], uma etapa descrita por Goodwin e Wright no qual descreve os indicadores que contribuirão para a construção de planos de ações [11]. O estudo realizou a pesquisa base sobre os métodos de planejamento de cenários, assim como o do resíduo e de suas aplicações. A etapas são mostradas na Figura 1.

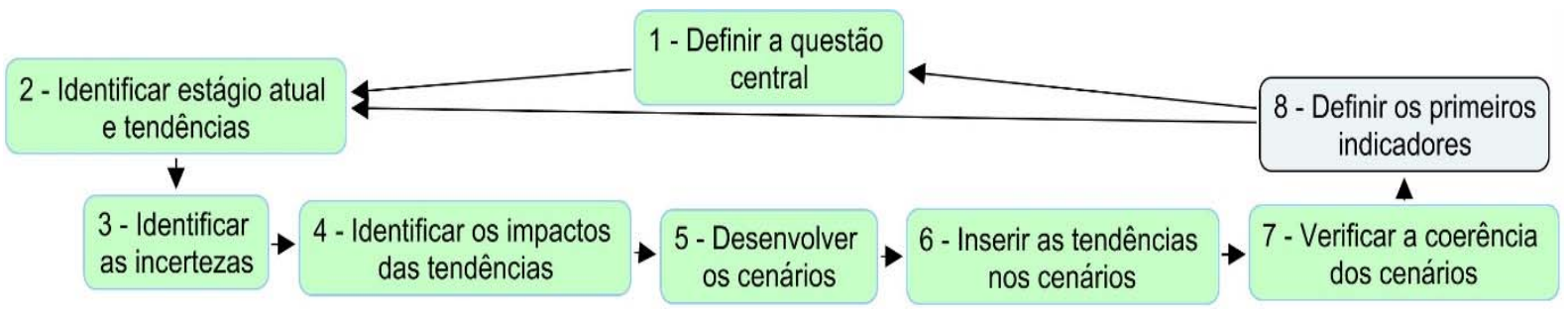

FIGURAErro! Nenhum texto com o estilo especificado foi encontrado no documento..1: Método proposto para a construção de cenários com base na escola Norte Americana. (Adaptado de [11]).

Os cenários prospectivos foram criados para dar alternativas de aplicação que viabilizem o uso deste resíduo no estado do Pará, considerando as estruturas industrias e logísticos locais. Shinomiya et al. desenvolveram o estudo até a $7^{a}$ etapa deste planejamento, gerando possíveis cenários de aplicação da Lama Vermelha [12]. Este trabalho adotou a construção dos cenários como ferramenta, prosseguindo até a etapa de seleção das alternativas de aplicação da Lama Vermelha. Para este trabalho, vale destacar que o estudo se limita a primeira etapa do método, a qual define a melhor aplicação do resíduo na indústria beneficiadora.

Definir a questão central (Etapa 1): Divide-se em duas tarefas: conhecer o resíduo e definir variáveis para a análise decisória. Para o resíduo, utilizou-se o mapa conceitual para construir um banco de informações como: características, técnicas de beneficiamento, propriedades físicas e químicas, e cada subitem foi descrito através de mapas estruturais.

Para o setor de aplicação, reúne-se informações sobre sua infraestrutura, distância, localização, capacidade produtiva etc. Estas variáveis, forças e fatores serão importantes para a construção dos cenários. O trabalho inicia-se em reunir com Stakeholders e decisores ou prospectar informações em banco de dados, comprometendo em parte o conhecimento de causa.

As informações coletadas sobre o rejeito foram agrupadas através de mapa conceitual e estrutural. Levantar dados sobre as potenciais indústrias beneficiadoras no estado, a logística, para assim, determinar critérios sobre os resíduos que: buscam o menor investimento em processamento, o número de indústrias locais disponíveis e a capacidade de processamento do rejeito. Encontrar o mercado que a lama vermelha poderá atingir e quais são as possibilidades de aplicações. 
Para ranquear as alternativas, fez-se o uso de uma abordagem parcial do método SMART, onde foram atribuídos pesos e valores estabelecidos pelo decisor. A atribuição dos valores foi definida através de dados da literatura. Para a avaliação das alternativas utilizou-se a Equação 1.

$$
V(a)=\sum_{i=1}^{m} w_{i} v_{i}(a)
$$

Onde $V(a)$ representa o valor associado a alternativa "a", $v_{i}(a)$ é a pontuação da alternativa "a" no i-ésimo critério e $w_{i}$ é o peso atribuído a "a".

Estes critérios respeitam axiomas como: completude, operacionalidade, possibilidade de decomposição, ausência de redundância e tamanho mínimo. O valor parcial é a soma dos produtos entre o peso e o valor de cada critério com as alternativas. $O$ resultado final é a pontuação para cada alternativa. A maior pontuação representa o potencial da aplicação do resíduo considerando os fatores locais.

Realizado a pontuação e o ranking final, uma análise mais profunda sobre a alternativa e sobre as unidades fabris existentes devem ser desenvolvidas dentro dos fatores: técnico, ambiental, econômico etc. Este artigo se limita a desenvolver o estudo até esta etapa do planejamento de cenários.

\section{RESULTADOS E DISCUSSÃO}

O reaproveitamento da lama vermelha ainda é desafiador para a indústria do alumínio, tendo em vista o grande volume produzido e estocado anualmente. Faz-se necessário pensar na reciclagem dos rejeitos da indústria da mineração como uma alternativa para diminuir o volume desses rejeitos nestes pátios de estocagem. A investigação dos dados adquiridos foi realizada em periódicos, relatórios de empresas, associações, bem como em normas técnicas. Ressaltando que este trabalho se limita apenas no ranking da aplicação adequada para o Estado limitando-se a primeira etapa do Planejamento de Cenários.

Definição da questão central (Etapa 1): Há enorme quantidade de rejeito alcalino sendo depositado em áreas abertas. Isto pode gerar grandes problemas ambientais se não forem monitorados de maneira adequada pelo responsável, então levantou-se as necessidades sobre maneiras possíveis de reduzir o montante acumulado do rejeito alcalino. Assim foram levantadas informações sobre: o resíduo e suas possíveis aplicações na literatura; as indústrias locais como: localização, produção mensal, mercado etc.; a infraestrutura que o estado pode oferecer para transportar o resíduo até a indústria beneficiadora.

Caracterização da lama vermelha: As características da lama vermelha são mostradas no mapa conceitual demonstrado na Figura 2. 


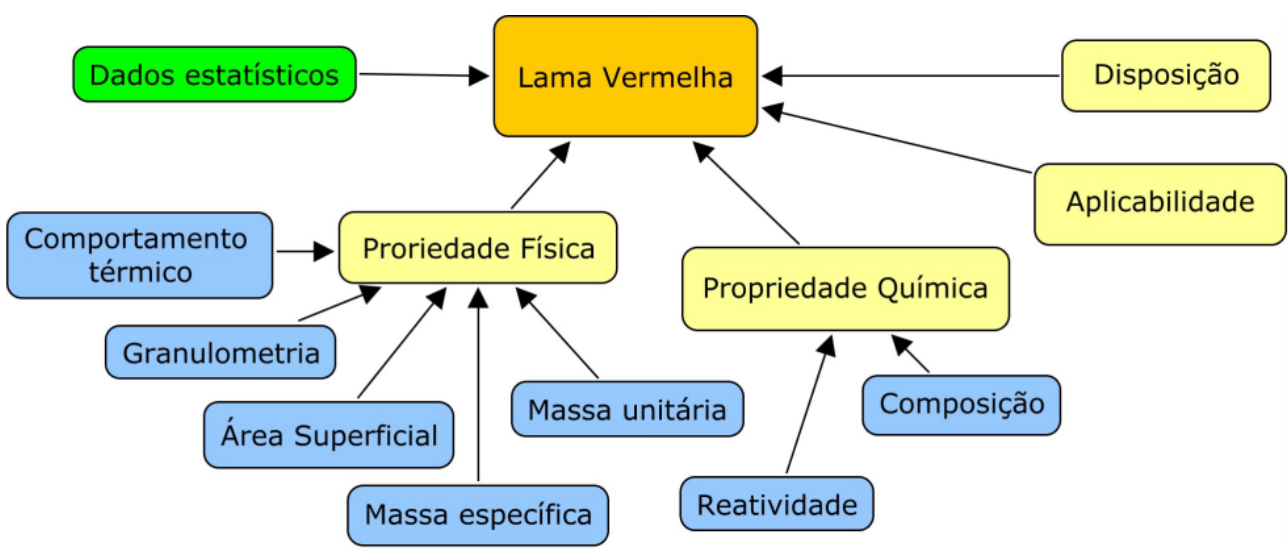

Figura 2: Mapa conceitual para a lama vermelha.

As propriedades físicas da lama como sua distribuição do tamanho de partículas, área superficial, massa específica, massa unitária e comportamento térmico são dados essenciais para comparar com agentes que podem agregar valor possibilitar seu reuso. A propriedade é descrita através do mapa estrutural mostrado na Figura 3.

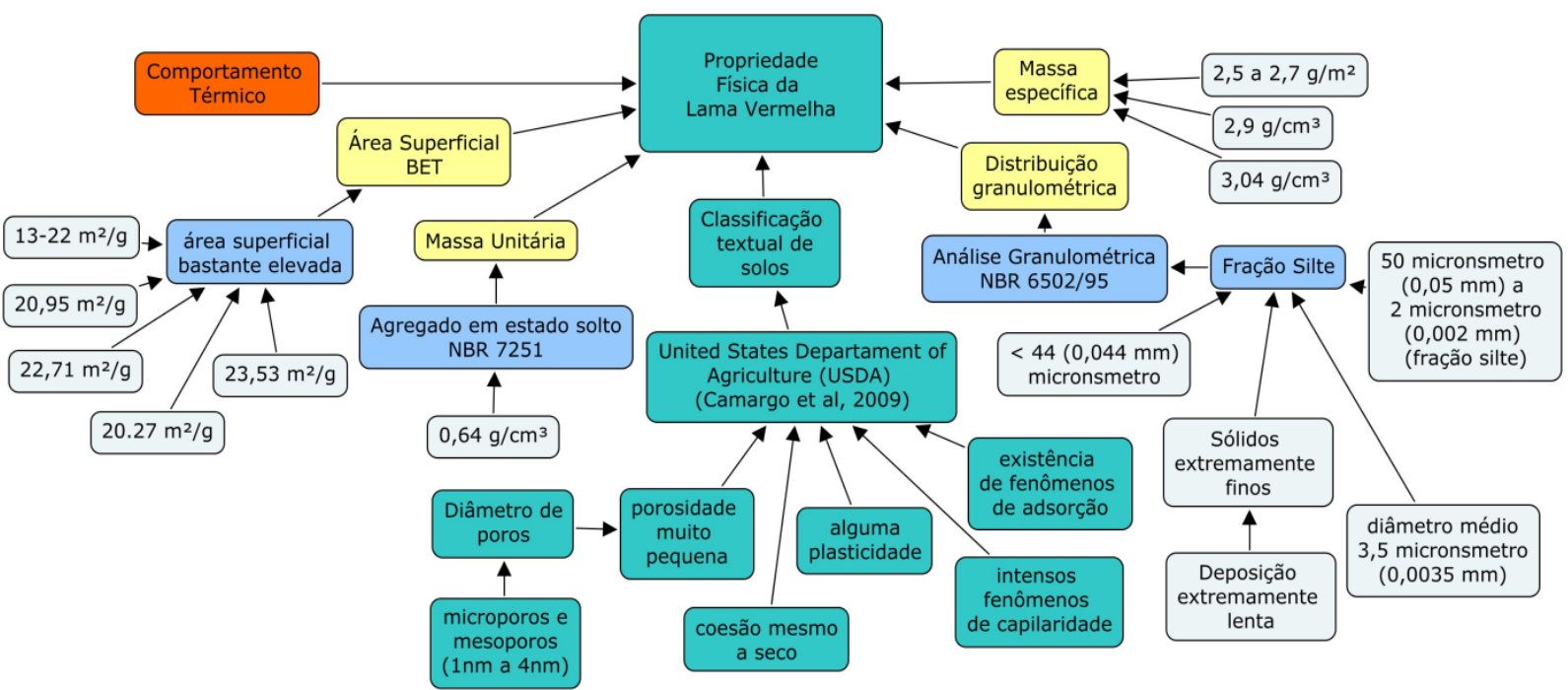

Figura 3: Mapa estrutural para o cluster propriedade física para a lama vermelha.

Nota-se que a granulometria varia de $44 \mu \mathrm{m}(0,044 \mathrm{~mm})$ a $2 \mu \mathrm{m}(0,002 \mathrm{~mm})$, sendo caracterizado pela ABNT como frações de "siltes" [13]. A elevada área superficial confirma a pequena granulometria da lama à temperatura ambiente.

Informações sobre o comportamento térmico identificaram algumas mudanças estruturais com a variação da temperatura como pode ser mostrado na Figura 4. 

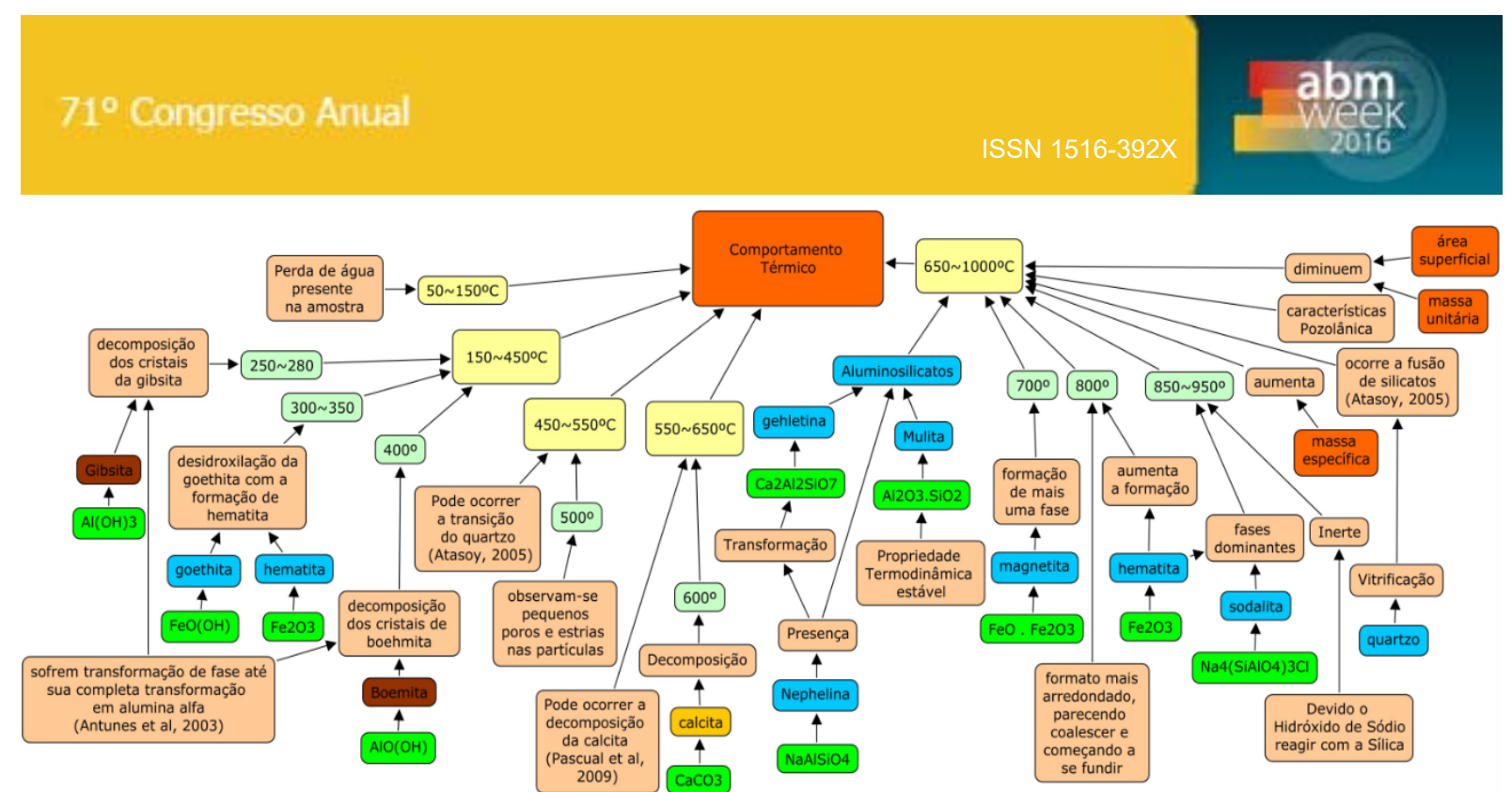

Figura 4: Mapa estrutural para o comportamento térmico para o resíduo.

As informações sobre a propriedade química da lama vermelha mostram variações composição química e mineralógica em função da região de extração da bauxita. A lama vermelha apresenta alto $\mathrm{pH}$, sendo alcalino próximo a 12. Este tende a diminuir com o tempo de armazenamento nas áreas de deposição [14]. Apresenta em maior parcela os óxidos de alumínio, ferro, silício, seguido dos sais dissolvidos, além da presença de alguns metais pesados como o zinco, o cromo e o bário, misturados em estruturas químicas complexas. A Figura 5 mostra a propriedade química para a lama vermelha. A composição média no mundo e no Brasil é apresentada na Tabela 1.

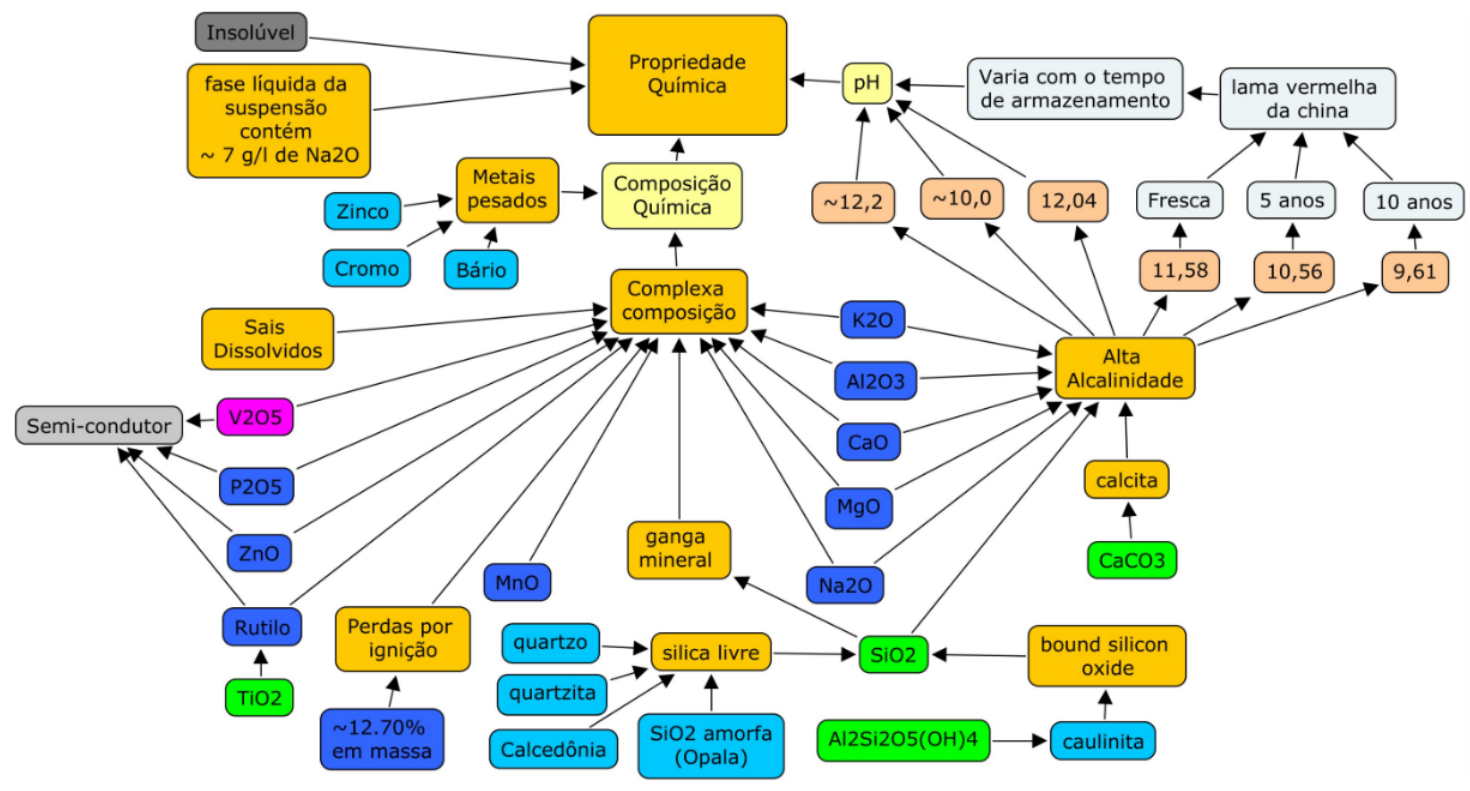

Figura 5: Mapa estrutural para a propriedade química do resíduo.

Tabela 1: Composição média da lama vermelha gerada no mundo e no Brasil.

\begin{tabular}{lccccccccc}
\hline Elemento & $\mathrm{Fe2O3}$ & $\mathrm{Al2O} 3$ & $\mathrm{SiO2}$ & $\mathrm{Na2O}$ & $\mathrm{TiO2}$ & $\mathrm{MgO}$ & $\mathrm{CaO}$ & Outros & P.F. \\
\hline no Mundo & 40,3 & 18,5 & 8,9 & 4,4 & 7,7 & 0,3 & 5,1 & 0,2 & 14,6 \\
no Brasil & 37,7 & 25,1 & 11,1 & 7,1 & 5,5 & 0,5 & 1,9 & 0,2 & 10,9 \\
\hline
\end{tabular}


A Figura 6 mostra o cluster para as aplicações do resíduo como matéria-prima já relatadas em estudos para a área da construção civil, química, agricultura, metalurgia e nuclear.

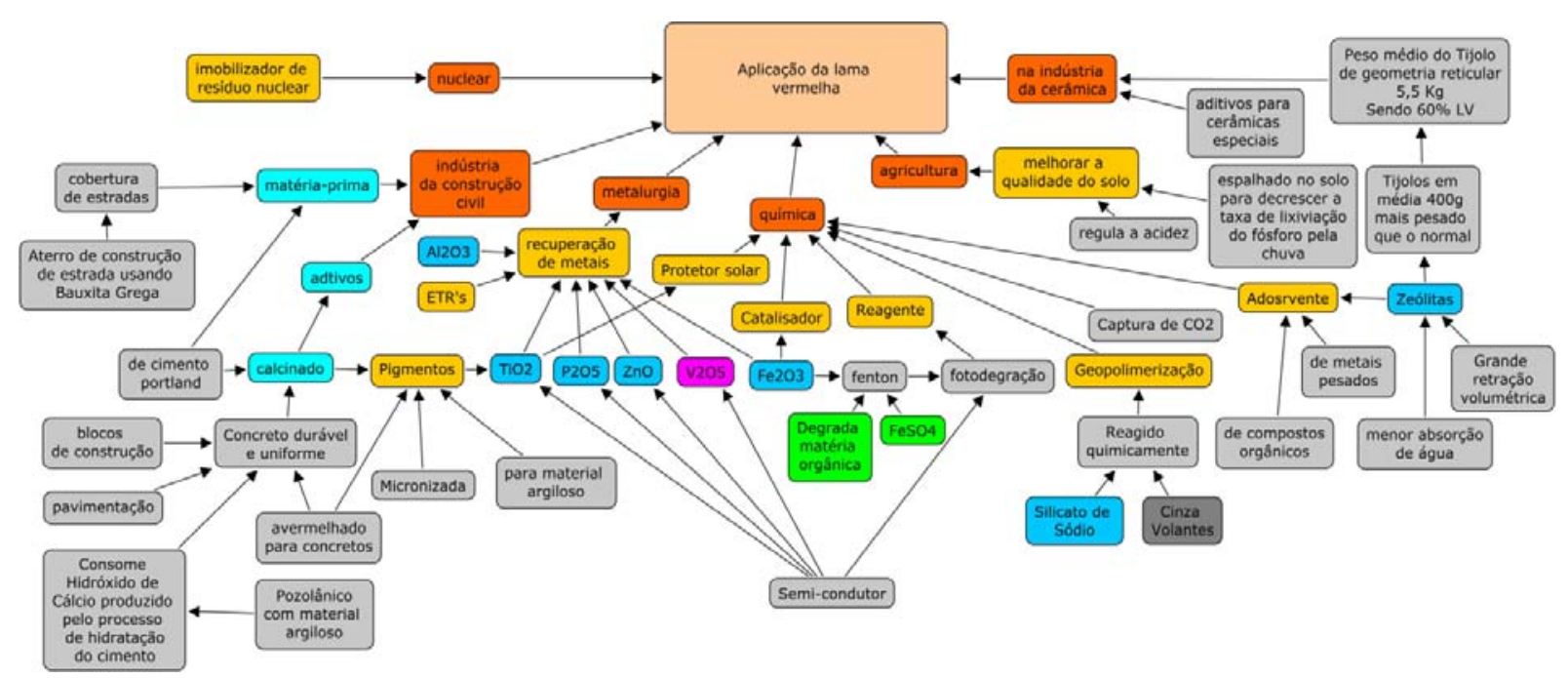

Figura 6: Mapa estrutural para as aplicações para a lama vermelha.

As opções de aplicação da lama vermelha no estado do Pará: O estado Pará ainda é uma federação cuja sua economia predominante ainda é a indústria extrativa, agropecuária e a construção civil. Foi definido que a aplicação do rejeito a ser aplicada no estado deve utilizar a infraestrutura industrial local. Para isso, critérios foram estabelecidos juntamente com o decisor como sendo: Processar o rejeito em indústrias do estado do Pará (Disponibilidade de Indústrias Próximas - DIP), este critério considera a quantidade de indústrias físicas que o estado possui para cada tipo de aplicação; utilizar o rejeito em grandes quantidades nas potenciais aplicações (Quantidade de rejeito utilizado - QRU), este critério considera a quantidade de rejeito inserido nas amostras para a aplicação; minimizar a necessidade de pré-tratamento do rejeito para aplicar como produto (Capacidade de receber o rejeito - QRR), este critério foi considerado o número de processos químicos necessários para tornar 0 resíduo aplicável. Os pesos para os critérios foram definidos pela importância para cada alternativa na tomada de decisão, onde são mostrados na Tabela 2.

Tabela 2: Peso e escala de valor para cada critério.

\begin{tabular}{|c|c|c|c|c|c|c|}
\hline & \multirow{2}{*}{ Peso } & \multicolumn{5}{|c|}{ Valor dos critérios à luz das Alternativas } \\
\hline & & M.alto & Alto & Médio & Baixo & Nulo \\
\hline 1. Quantidade de rejeito utilizado (QRU) & 34,0 & 1 & 0,75 & 0,5 & 0,25 & 0 \\
\hline Considerações* & --- & $>4$ & 3 & 2 & 1 & 0 \\
\hline 2. Disponibilidade de Indústria Próxima (DIP) & 30,2 & 1 & 0,75 & 0,5 & 0,25 & 0 \\
\hline Considerações** & --- & -- & 0 & 1 & $>2$ & -- \\
\hline 3. Capacidade de receber o rejeito (CRR) & 35,8 & --- & 1 & 0,5 & 0 & --- \\
\hline
\end{tabular}

* Quantas indústrias no ramo estão presentes?

** Quantos processos químicos são necessários para preparar o resíduo para a aplicação?

*** É necessário Tratamento Químico? 
Os valores para os critérios para cada aplicação foram definidos de acordo com as informações coletadas e através da equação 1 , onde as multiplicações dos critérios ocorreram a luz das alternativas. Com os cálculos dos pesos e dos valores dados, a alternativa melhor ranqueada é mostrada na Tabela 3.

Tabela 3: Resultado dos valores para as aplicações.

\begin{tabular}{lcccc}
\hline \multicolumn{1}{c}{ Aplicação } & QRU & DIP & CRR & Valor \\
\hline Construção de estradas & 0,75 & 1 & 1 & 91,5 \\
\hline Produção de cerâmica vermelha & 0,6 & 1 & 1 & 86,4 \\
\hline Produção de cimento & 0,25 & 1 & 1 & 74,5 \\
\hline Adsorventes & 0,75 & 0,25 & 0,5 & 50,9 \\
\hline Imobilizador de rejeito nuclear & 0,25 & 0 & 1 & 44,3 \\
\hline Melhoramento de solos & 0,5 & 0 & 0,5 & 34,9 \\
\hline Catalisadores & 0,75 & 0,25 & 0 & 33,0 \\
\hline Geopolímeros & 0,1 & 0 & 0,5 & 21,3 \\
\hline $\begin{array}{l}\text { Extração de elementos } \\
\text { estratégicos }\end{array}$ & 0,25 & 0 & 0 & 8,5 \\
\hline
\end{tabular}

Através dos critérios estabelecidos, verificou-se as aplicações mais adequadas para o estado como: construção de estradas e produção de cerâmica vermelha e produção de cimento.

A pavimentação de estradas, o qual foi a maior ranqueada devido a sua pontuação no critério quantidade de rejeito utilizado e capacidade de receber o rejeito sem tratamento. No entanto, esta opção tem a necessidade da adição de cimento para transformar em um pavimento, o qual o cimento possui uma produção limitada devido a estrutura das unidades fabris, além disso, a produção local de cimento não consegue suprir o mercado interno e vem sendo importado de outros estados. O uso direto sem a adição do cimento tecnicamente é possível, no entanto, ainda é necessário avaliar o comportamento da deposição da lama vermelha sobre o solo devido seu pH muito básico, o que pode ocasionar danos as cascas dos automóveis e da presença de metais pesados em sua composição. Para o caso do cimento e da cerâmica vermelha, os metais pesados podem ser imobilizados no processo de cura da cerâmica vermelha e no cimento.

\section{CONCLUSÃO}

A primeira etapa do planejamento de cenários define as possíveis aplicações considerando as indústrias locais que podem beneficiar a Lama Vermelha. Esta etapa auxilia na escolha entre as possíveis aplicações para este resíduo, fazendo-se o uso de ferramenta de ranking entre as alternativas que considera a estrutura da indústria local, atribuindo valores e pesos, contribuindo também para o auxílio do tomador de decisão. As principais aplicações definidas nesta etapa de ranqueamento sendo da maior pontuada para a menor foram: a pavimentação de estradas, produção de cerâmica vermelha e a produção de cimento. Estas alternativas servirão para a construção das próximas etapas do planejamento de cenários. A realização da primeira etapa do planejamento de cenário mostrado neste trabalho pode ser estendida também para outros tipos de resíduos, coletando informações necessárias como suas propriedades químicas, físicas e mineralógicas, bem como da indústria que irá beneficiar o resíduo. 


\section{REFERÊNCIAS}

1 FERREIRA, A. B. H. Novo Dicionário Aurélio da Língua Portuguesa. $3^{a}$.ed. São Paulo: Positivo; 2004.

2 CHIAVANETO, I. Introdução à Teoria Geral da Administração. Rio de Janeiro: Elsevier; 2003.

3 ALLAIRE, C. Use of red mud for the production of aluminium reduction cell potlining refractories. Light Metals: TMS Proceeding. 1992; p. 401-406.

4 SILVA FILHO, E.B., ALVES, M.C. M., DA MOTTA, M. Lama vermelha da indústria de beneficiamento de alumina: produção, características, disposição e aplicações alternativas. Revista Matéria. 2007. Vol. 12. p. 322 - 338.

5 RESENDE, E.C. Aplicação da lama vermelha como catalisador em processos oxidativos/redutivos. Universidade Federal de Lavras, Minas Gerais. Tese de Doutorado (Doutorado em Agroquímica); 2012

6 SCHWARTZ, P. A Arte da Visão de Longo Prazo: Planejando o futuro em um mundo de incertezas. São Paulo: Best Seller; 2000.

7 GODET, M. The Art of Scenarios and Strategic Planning: Tools and Pitfalls, Technological Forecasting and Social Change. Elsevier Science Inc. New York; 2000.

8 Schoemaker, P. Gunther, R.E. Profiting from Uncertainty: Strategies for Succeeding No Matter What the Future Brings. Atria Books; 2002

9 RINGLAND, G. Scenario Planning: Managing for the future. New York: Willey; 1998.

10 PORTER, M. E. Competitive advantage. New York: Free Press; 1985

11 GOODWIN, P., WRIGHT, G. Decision analysis for Management Judgment. $3^{\text {th }}$ ed. John Wiley \& Sons Ltd; 2004.

12 SHINOMIYA L. D, GOMES J. O. E ALVES, J. O. Planejamento de cenários para uso de resíduos industriais: aplicação para lama vermelha. Revista Gestão em Engenharia, 2015. v.2, n.2, p.43-66.

13 ABNT - ASSOCIAÇÃO BRASILEIRA DE NORMAS TÉCNICAS, Rochas e solos, NBR 6502, ABNT, Rio de Janeiro, 1995.

14 Lin, C., Liu Y., Wu, Y. Characterization of red mud derived from a combined Bayer Process and bauxite calcination method. Journal of Hazardous Materials. 2007; Vol. 146, p. 255-261. 